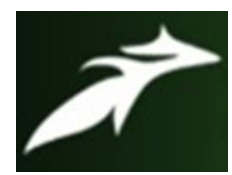

Gadona Enoch Alhamdu et al, International Journal of Advances in Agricultural Science and Technology,

Vol.7 Issue.11, November-2020, pg. 100-111

ISSN: 2348-1358

Impact Factor: 6.057

NAAS Rating: 3.77

\title{
MAPPING OF GULLY AREAS USING GIS AND REMOTE SENSING IN PART OF MUBI SOUTH/MUBI NORTH LOCAL GOVERNMENT AREA
}

\author{
Gadona Enoch Alhamdu'; Gamaniel Japheth ${ }^{2}$; Elisha Tizhe Faive ${ }^{3}$ \\ Department of Surveying and Geoinformatics, Federal Polytechnic, Mubi, Adamawa State, Nigeria \\ DOI: 10.47856/ijaast.2020.v07i11.014
}

\begin{abstract}
Gully erosion is one of the most serious environmental problems in the world today, it threatens, the natural environment. This study used Geographic Information System (GIS) and Remote Sensing to study Gully erosion based on band ratio formula method. Quick Bird satellite image of 2015 was used as base map to delineate the boundary of the study area. LandSat TM of 2010 was used to generate gully erosion map of the study area, $100 \mathrm{~m}$ steel tape was used to measure the width, depth and length of the gullies. Photographs were taken using digital camera. Database was created and the photographs were link with table which enable simple query and analysis of the gullies in pictorial forms to be done. The band ratio formula was carried out using ArcGis 10.0 software. The research findings indicated high eroded gullies are of high intensity and are bare lands whereas less eroded gullies are of less intensity and are low slope areas. The study recommends the use of GIS and Remote Sensing for efficient and effective management of gully erosion. Keywords: Gully Erosion, Mapping, Delineation, Boundary, Satellite
\end{abstract}

\subsection{Introduction}

Soil erosion is the physical removal of materials (soil particles) from one place to another. It is an accelerated process under which soil is bodily displaced and transported away faster than it can be formed. According to Fairbridge, (2008), gully erosion is an incised cut step - sided channel, with an eroding head cut and slumping sidewalls.

Gullies are deep depressions, channels or ravines in a landscape caused by water action. Gullies occur when runoff water is channeled into grooves and deepen over time forming a distinct head with steep sides that may collapse by water seepage or undermined by water flow within the gully (Stocking \& Murnaghan, 2000).

Soil erosion is one of the most serious environmental problems in the world today because it threatens agricultural as well as the natural environment Nuket (2009); Hence a comprehensive information on soil resources, its potential, limitation and capabilities is required for a variety of purpose such as command area development, conservation in catchment area, reclamation of degraded lands, watershed management etc. 


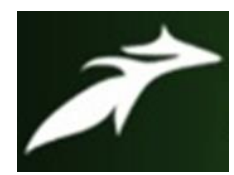

Gadona Enoch Alhamdu et al, International Journal of Advances in Agricultural Science and Technology, Vol.7 Issue.11, November-2020, pg. 100-111

ISSN: 2348-1358

Impact Factor: 6.057

NAAS Rating: 3.77

According to Akintola (1978) sees that natural hazard have become an issue of growing concern throughout the big towns and cities of the world today. The frequency as well as the magnitude of the related disaster threatening large population living in different area, location or environment, that shows a dramatic rise in recent years, environmental hazard which affect the human activities, properties and the lives of people.

Also according to Nwanko and Ifeadi(1996), environmental degradation in Niger Delta is as a result of extraction of natural oil resources over the years in the areas and is not only a product of unequal exchange in international trade and export, it can also be seen from perspective of the inherent contradiction in the production.

Gullies normally have a distinctive propagation head, which is the morphological expression between stable and unstable regimes (Rebeiro-Hargrave 2000). The development of gullies represents a specific type of fluvial erosion that is triggered when surface runoff becomes concentrated on parts of a slope during extreme rainfall events (Zachar, 1960). These gullies commonly develop as deeply incised features in soft sedimentary materials such as the loess of Belgium (Nachtergaele \& Poesen, 1999; Nachtergaele et al. 2002) and marls of southern Spain Harvey (Wells, 1987). In south eastern Nigeria, gully erosion is responsible for the destruction of transportation and communication systems, degradation of arable land, contamination of water supply, isolation of settlements and migration of communities. More than 2,500 gullies are active (Egboka, 2004).

Gully erosion has been a big problem to many cities; the impact of gully erosion on the environment has been physically seen and acknowledged in Barama/Gipalma and Murracha in Mubi north and Mubi south LGAs. Some of the problems associated with gully erosion in the study area include washing away of the soil caused by decline in land productivity and reduced agricultural production leading to low income to the farmers. In some part of the study area, residence experience enormous damage of farm lands, houses, road and buildings. This situation result in flooding causing a lot of damages. It has become necessary to the state to take urgent steps to control the situation, one of which is to have a digital map of the gully erosion in the study area for planning and management purposes. 


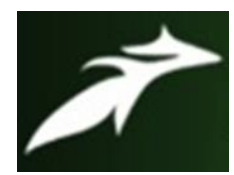

Gadona Enoch Alhamdu et al, International Journal of Advances in Agricultural Science and Technology, Vol.7 Issue.11, November-2020, pg. 100-111

ISSN: 2348-1358

Impact Factor: 6.057

NAAS Rating: 3.77

Before the advent of remote sensing techniques, the soil surveys were conventionally carried out at reconnaissance, detailed reconnaissance level depending on the requirement. In all these three method, soil mapping is done after field observation. Later, aerial photographs were used as remote sensing tool in soil mapping and because of some technical limitations they could not be operational in soil mapping. The application of Remote sensing techniques have reduced field work to a considerable extent and soil boundaries are more precisely delineated than the conventional method which was achieved with the lunch of LandSat 1 in 1972 (Fagbami, 1986).

Soil erosion over Earth is a quite-frequent and well-distributed problem. Mapping the level of risk of areas subjected to rain and wind erosion is therefore all important issue. Models of soil erosion highlight the importance of soil coverage by active green vegetation and residue. When soils are covered by senescing vegetation or crop residue, the cover fraction is often very low and may coincide with heavy rainfall events. It has been demonstrated that a $15 \%$ cover fraction by corn residue reduces soil run off by $75 \%$ (Melesse and Jordan, 2002).

In the past, comprehensive analysis of gullies has often been neglected by the scientific community. For example, a review by Casali et al (2009) shows that less than 10\% of soil erosion studies around the world address gullies directly. However, in order to develop strategies to control, prevent and rehabilitate gullies, the spatial extent of the problem has to be established and monitored (Le Roux et al., 2007; Kakembo et al., 2009). Geographic Information Systems (GIS) and Remote Sensing (RS) technologies have been frequently used to assess soil erosion features.

The research study is aimed at the studying and mapping out the gully erosion in the study area with the view of finding solution to soil erosion so as to enhance the economic activities. The aim could be achieved through Mapping of the gullies in the study area with satellite images. The research work will be of importance to the communities in the study area, as it will assist in overcoming the setback experience in socio-economic development of area by examining the specific human activities for land degradation. This would assist urban planners and agriculturalist by providing a lasting solution to counter the threat of erosion in 


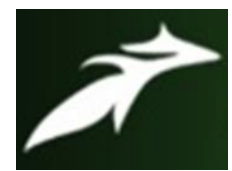

Gadona Enoch Alhamdu et al, International Journal of Advances in Agricultural Science and Technology,

Vol.7 Issue.11, November-2020, pg. 100-111

ISSN: 2348-1358

Impact Factor: 6.057

NAAS Rating: 3.77

terms of loss of farmlands and damages to buildings and roads and enhance the economic activities in the study area.

\subsection{Study Area}

The study area is located between latitude $10^{\circ} 00^{\prime}$ to $10^{\circ} 13^{\prime}$ and longitude $13^{\circ} 00^{\prime}$ to $13^{\circ} 16^{\prime}$ and is approximately $187 \mathrm{~km}$ North West of Adamawa State capital, Yola. The area is in Mubi North and Mubi South with an area of 379.6 Hectares with population of 13560 people based on 2006 National Population Census. (See Figure 1)

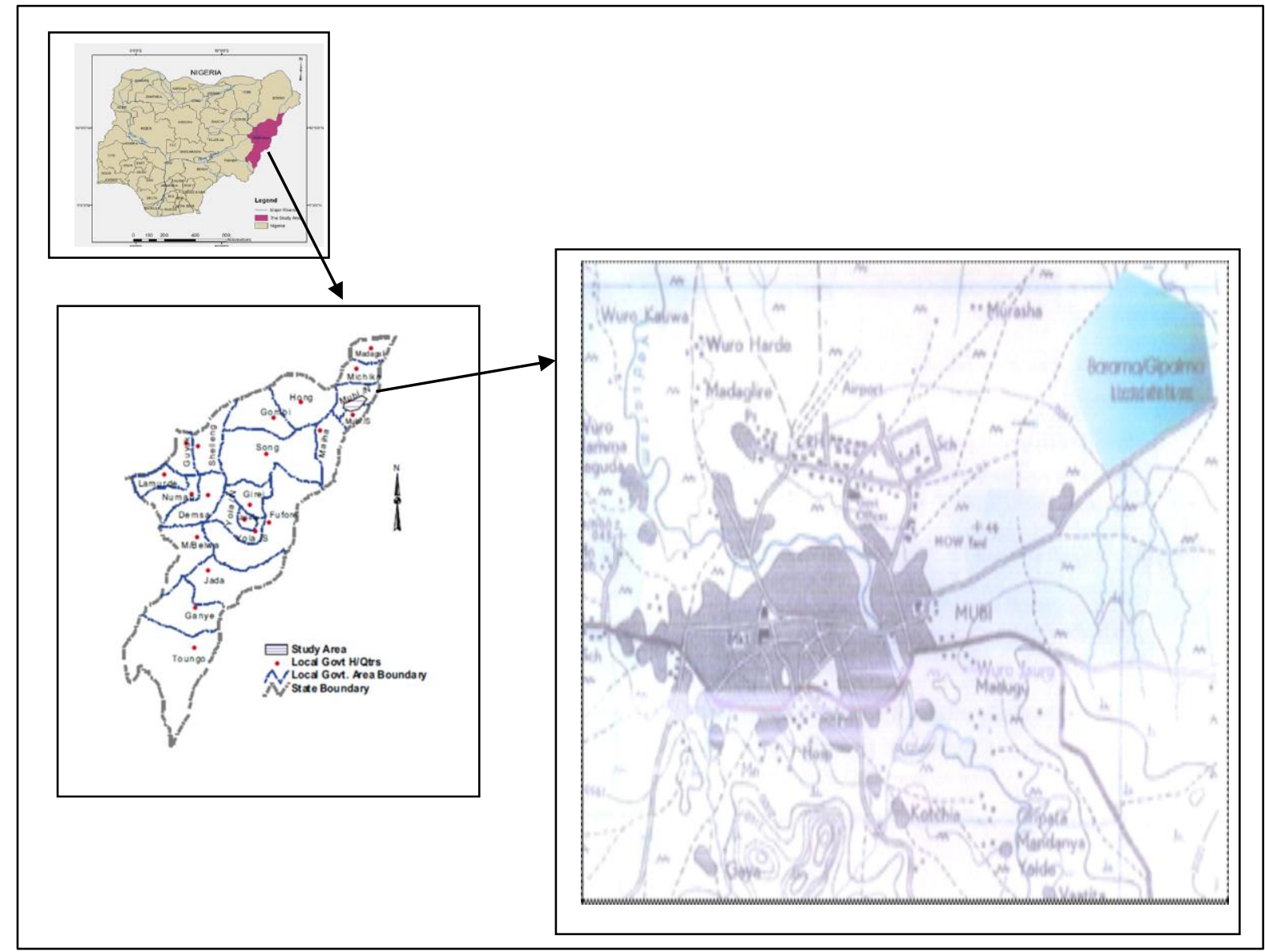

The study area falls within the Sudan Savanna belt of the Nigeria's vegetations zones (Yonanna, 2004). The regions vegetation type is best described as combretaceous woodland Savanna. It is made up of grasses, aquatic weeds in the valleys and dry land weeds inter spaced by thorny bushes wooded shrubs and trees. 


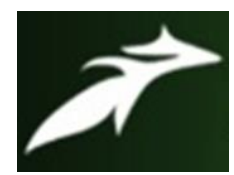

Gadona Enoch Alhamdu et al, International Journal of Advances in Agricultural Science and Technology, Vol.7 Issue.11, November-2020, pg. 100-111

ISSN: 2348-1358

Impact Factor: 6.057

NAAS Rating: 3.77

\subsection{METHOD AND MATERIALS \\ 2.1 Instrument Used}

The instrument used in the field for data collection and processing include the Hardware and Software which consist of Single Frequency GPS, Computer system and accessories, Flash Disk of 512 MB storage capacity and ArcGIS 10.0 version software, all for data collection, data input and data analysis. Others include; One Hewlett Packard (HP) 1310 colour printer; Nikon digital camera for printing and terrestrial photographs.

\subsection{Source of data}

The main sources of data used for the research work include Satellite images (Quick Bird of 1999 and LANDSAT 2010). The Quick Bird satellite images of 1999, covering the whole of Mubi (north and south) local government was used as a guide from which the exact location of the study area were determine or extracted (Barama, Muracha and Gipalma), is done by clipping the extent of the boundaries identified on satellite images.

The conceptual frame work model (Figure 1) depicts the process followed from the beginning of this research to the end which entails data capture, data input, data analysis, data manipulation and the final output. The LandSAT TM and QuickBird image of the studied area was acquired; the QuickBird image was used as the base map, to enable the reconnaissance survey and identification of the research area, the Band 3 and Band 4 were used to mapped the existing gullies through the raster calculator of ArcGIS 10.0 software as acknowledged by band ratio formula as slated below;

$$
\mathrm{A}=(\mathrm{B} 4-\mathrm{B} 3) /(\mathrm{B} 4+\mathrm{B} 3+\mathrm{K}) *(1+\mathrm{K}-\mathrm{value}) \quad \text {---------- Equation (3 in 1) }
$$

Where; 'A' implies gully, B4 implies Band 4 of the Landsat images.

B3 is the Band 3 of the Landsat images.

$\mathrm{K}$-value stands for soil factor of the area. 


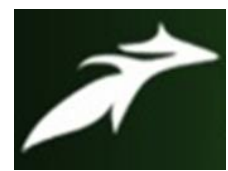

Gadona Enoch Alhamdu et al, International Journal of Advances in Agricultural Science and Technology,

Vol.7 Issue.11, November-2020, pg. 100-111

ISSN: 2348-1358

Impact Factor: 6.057

NAAS Rating: 3.77

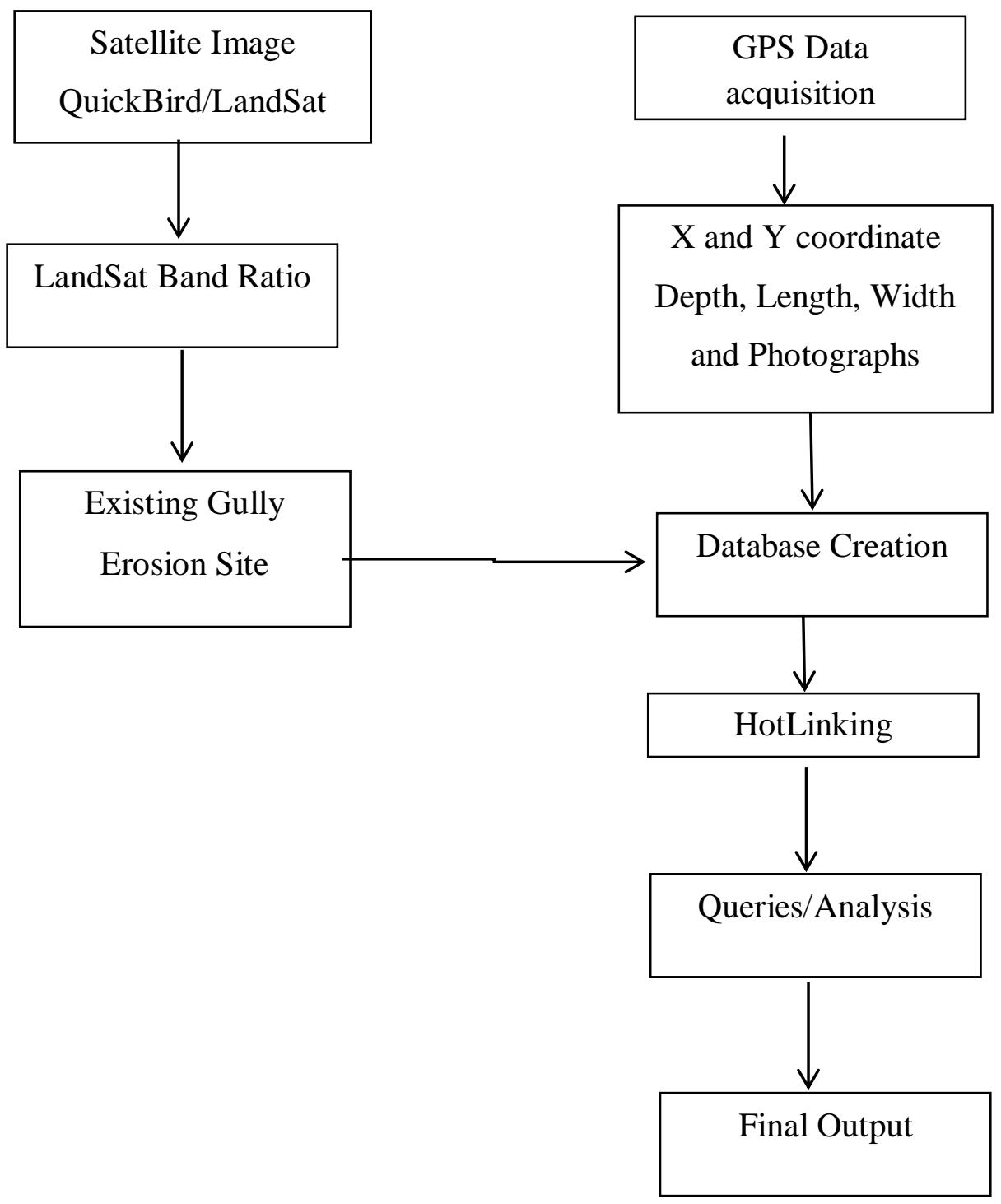

Figure 1: Conceptual Framework of Gully Erosion Analysis

\subsection{Landsat Tm (2010)}

Gully erosion map of the study area was generated from LANDSAT satellite imagery which shows all existing gullies in the study area of both low and high densities. This was achieved using Image Band ratio formula in equation 3 in 1 


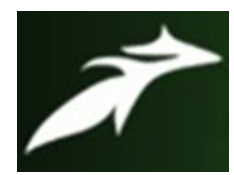

Gadona Enoch Alhamdu et al, International Journal of Advances in Agricultural Science and Technology, Vol.7 Issue.11, November-2020, pg. 100-111

ISSN: 2348-1358

Impact Factor: 6.057

NAAS Rating: 3.77

\subsection{Data Acquisition and processing}

A field observation trip has been carried out in order to collect the ground control points or coordinate $\mathrm{x}$ and $\mathrm{y}$ of some major gully erosion in the study area shown on the satellite images using single frequency Global positioning system (GPS) Receiver in the research area. Data collected from the field were process using ArcGIS 10 to produce the map of gully erosion. A database was created in row and column in which all the geometric characteristic of the gullies measured on the field and the respective photograph linked to gullies shown on satellite images.

A simple database table was created using ArcGIS by adding new database table using start editor and click to add fields of the geometric characteristics of the gullies determined from field observation (length, depth, width and coordinate), and photographs of the existing gully images was hot link with data base table to enable simple query and analysis.

The query of some information was carried out by the use of the query language tool through the table option and select by attribute commands in the Arc GIs tools. The select by attribute table opens with clause selection of record. The hyperlink tool was click on and icon tools highlighted. With the identifier tools, click on the attribute location point to display the information concerning the particular gully erosion of interest

\subsection{RESULTS}

\subsection{Gully location map of the study area}

The figure below shows the gully spot of the area plotted in $\mathrm{X}$ and $\mathrm{Y}$ coordinates from the ground survey data. It was overlaid on the Quick Bird image that was used as a base map of the study area as shown in figure 2.

\subsection{Quick bird image showing study Area}

Quick Bird image enables identification and delineation of the study area so as to give good judgement of the environment and to familiarize and study the effect of the gullies within the research area as depicted in figure 2. 


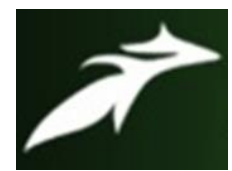

Gadona Enoch Alhamdu et al, International Journal of Advances in Agricultural Science and Technology,

Vol.7 Issue.11, November-2020, pg. 100-111

ISSN: 2348-1358

Impact Factor: 6.057

NAAS Rating: 3.77

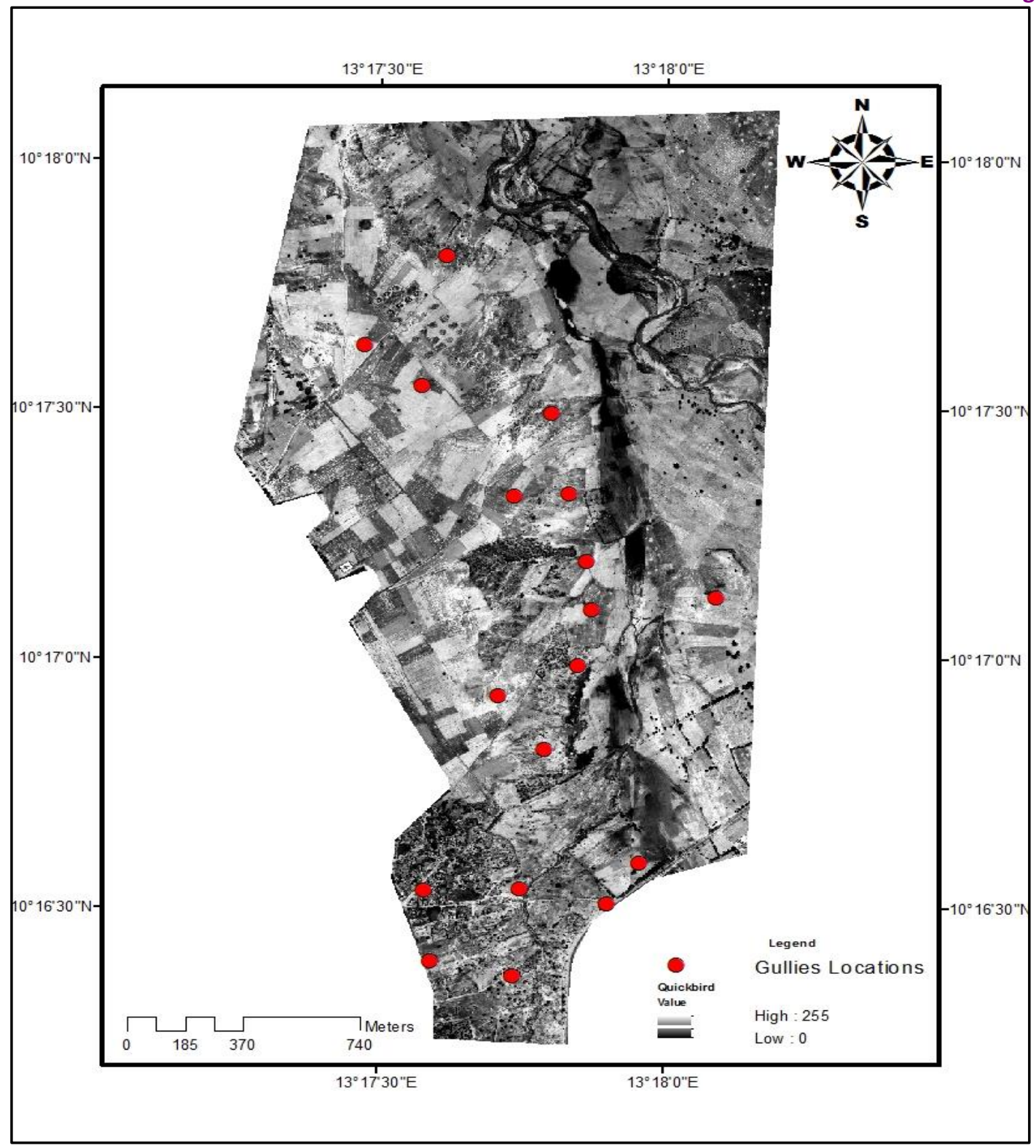

Figure 2: Quick Bird image of the study Area overlaid on gully locations which are in red circles.

\subsection{Existing gullies from band 4 and band 3}

Figure 2 shows the existing gully image of the study area which was achieved by the analysis using band ratio formula, that is using band 4 and band 3 and the soil factor $\mathrm{k}$ as discussed earlier. This shows that all the gully areas with high intensity appears in white and low intensity appears in grey, moist soil in brown which is liable to develop into gullies, when not mitigated. 


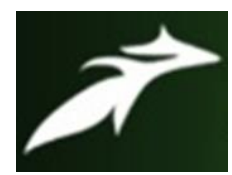

Gadona Enoch Alhamdu et al, International Journal of Advances in Agricultural Science and Technology, Vol.7 Issue.11, November-2020, pg. 100-111

ISSN: 2348-1358

Impact Factor: 6.057

NAAS Rating: 3.77

Gully erosion formed in different areas shows different characteristics. This is as a result of variation Gully in climate, water, velocity, vegetation, topography and land use practice. The geometric properties of the gullies that are vital to their interpretation and analysis from field data are those that described their topography, expression such as dimension, shape and special features.

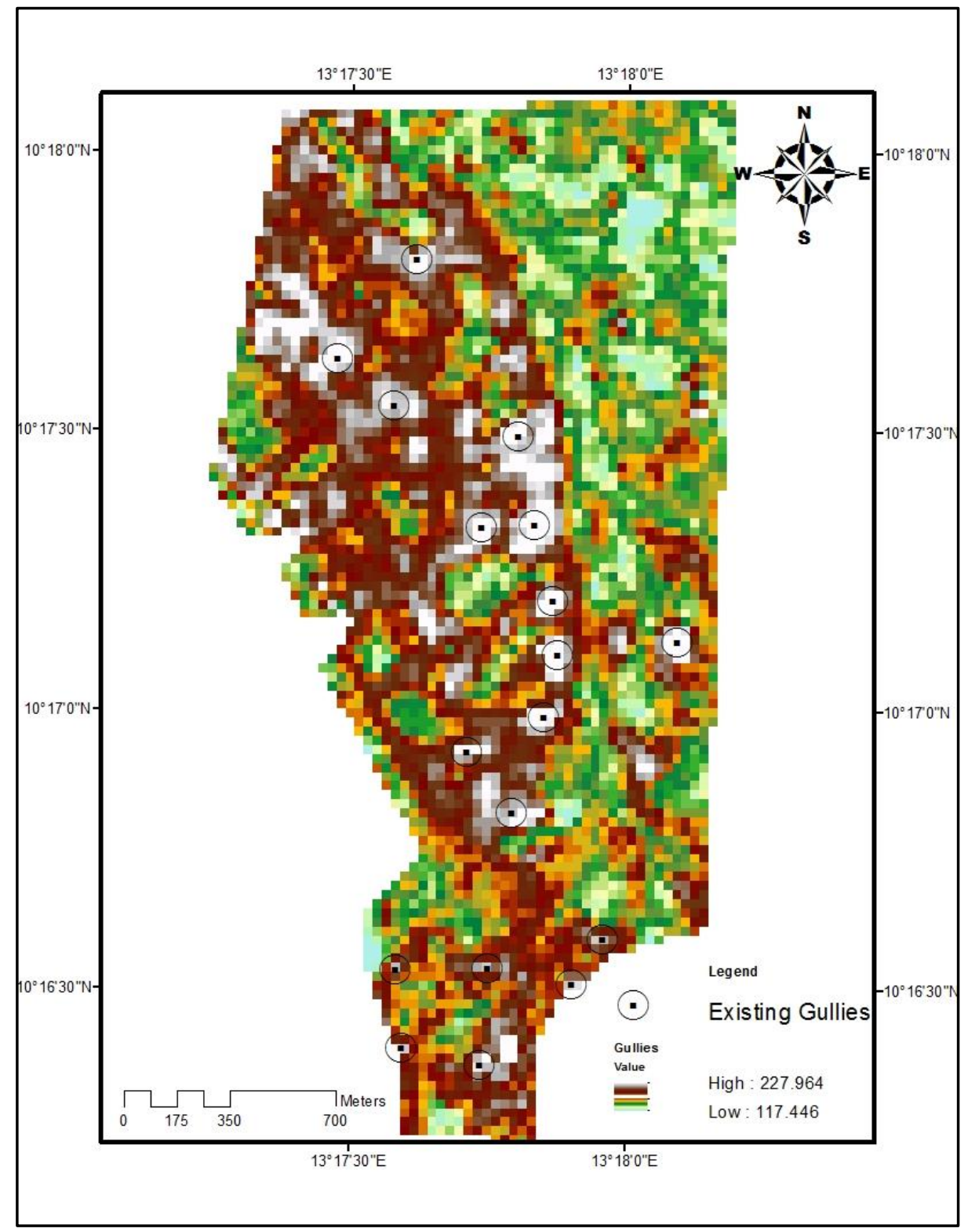

Figure 3: Shows the Existing Gully Erosion in white colour with High Intensity, non-existing gully erosion in the Study Area. 


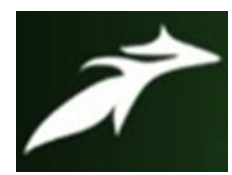

Gadona Enoch Alhamdu et al, International Journal of Advances in Agricultural Science and Technology,

Vol.7 Issue.11, November-2020, pg. 100-111

ISSN: 2348-1358

Impact Factor: 6.057

NAAS Rating: 3.77

\subsection{DISCUSSION}

\subsection{Length, Width and depth}

The Length of degradation area (gullies) in relatively impervious material such as clay or silt tend to be longer than those formed in most granular material like sand and gravel. The length of the channel is directly proportional to both the erosion, Susceptibility of the material and the frequency, duration, volume and velocity of the run-off.

The depth of the gully refers to the horizontal distance between its upper erosion scarp surface and ozone's. The depth is the vertical distance from the scarp surface to the bottom of the gully. Width, depth, and perimeter of the gully are closely related to the age of the gully, the hypnology of the flow and the type of material in which the gully is formed,

\subsection{Query for feature selection using (SQL)}

Having analysed all the satellite images using band ratio formula method and expanded their attributes which was hotlink with terrestrial photographs for selecting either the spatial data or the attribute features into categories were set. The multimedia query was carried out by the use of Hyperlink tool to depict the pictorial view of the particular gully point of emphasis as shown in the figure 4.

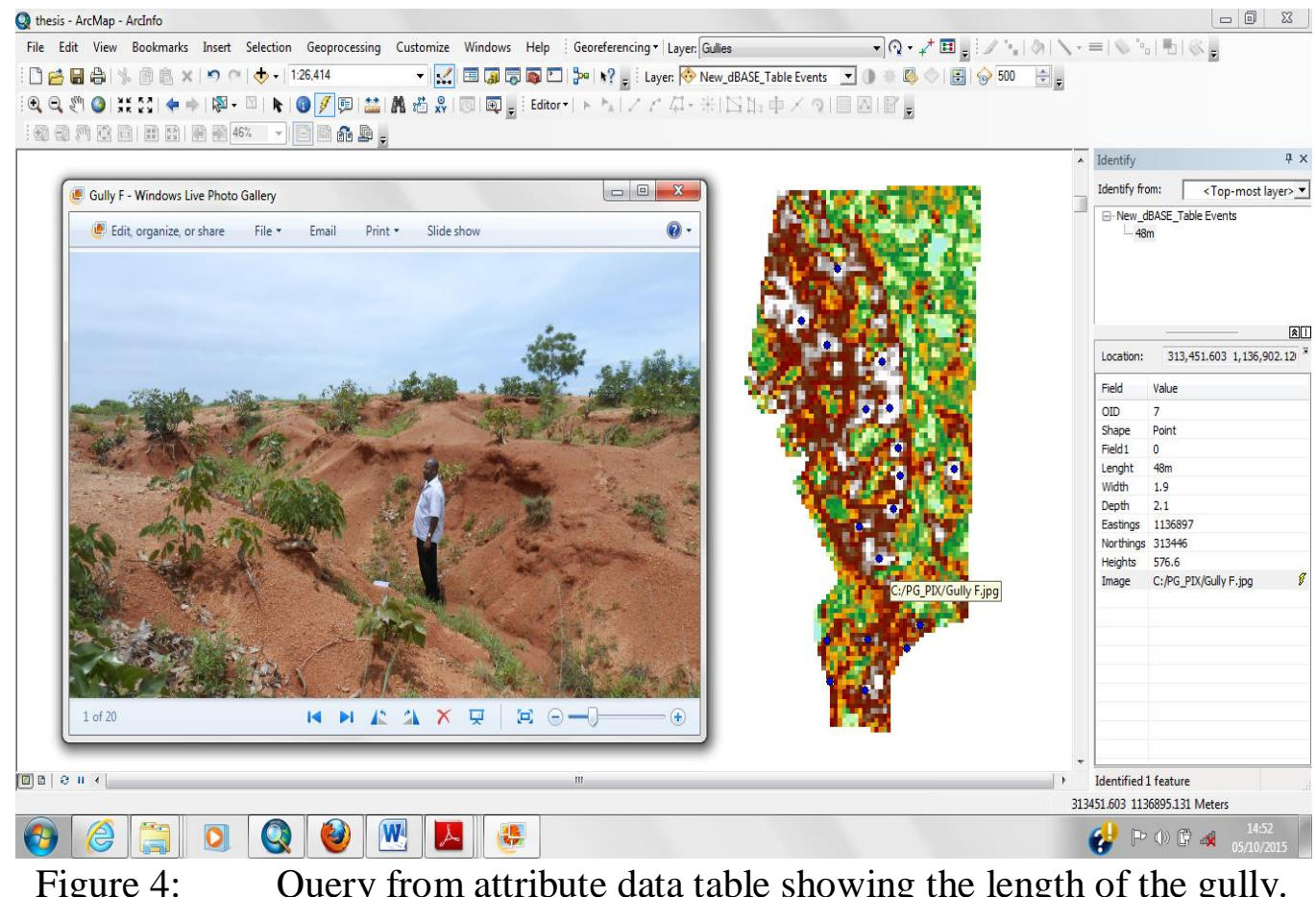




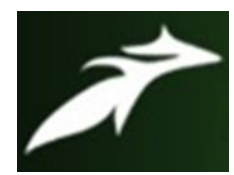

Gadona Enoch Alhamdu et al, International Journal of Advances in Agricultural Science and Technology,

Vol.7 Issue.11, November-2020, pg. 100-111

ISSN: 2348-1358

Impact Factor: 6.057

NAAS Rating: 3.77

\subsection{Recommendation}

From the research, it is recommended that the following are established and undertaken to address gully erosion;

a) It is recommended that the use of Revised Universal Soil Loss Equation (RUSLE) can be adopted to depict soil erosion areas and its effect on agricultural productivity. The method include some new and revised Isoerodent maps; a time - varying approach for soil erodibility factor, a sub factor approach for evaluating the cover management factor.

b) From Landsat satellite imagery, it is also recommended that ERDAS imagine software can be used to extract land/cover data using the supervised method of remotely sense data for gully erosion mapping.

c) It is also recommended that polarization combination $\mathrm{HH}$ (Horizontal polarization in transmitting and receiving direction), provide a better discrimination of eroded areas than polarization $\mathrm{HV}$ or $\mathrm{VV}$ polarization. Hence, ALOS/PALSAR HH polarization can be used to detect gully erosion in a study area.

d) The removal of sand and clay for commercial purposes which deepen and widen the rivers has to be regulated

e) The improper disposal of waste which blog the water channels resulting to erosion must be monitored

f) Deforestation which exposes the bear soil to erosion must be given due consideration and concern to regulate the rate of deforestation 


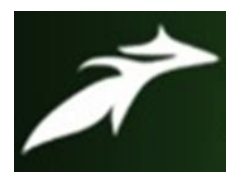

Gadona Enoch Alhamdu et al, International Journal of Advances in Agricultural Science and Technology,

Vol.7 Issue.11, November-2020, pg. 100-111

ISSN: 2348-1358

Impact Factor: 6.057

NAAS Rating: 3.77

\section{REFERENCES}

[1]. Akintola, F. O. (1978), Hydrological Consequences of Urbanization: A case Study of Ibadan City in Sada and Ogutoyinbo (Eds) Urbanization Process and problems in Nigeria Ibadan University Press Ltd. pp $151-155$

[2]. Casali, J., Gimenez, R \& Bennett, S 2009, 'Gully erosion processes: monitoring and modelling', Earth Surface Processes and Landforms, vol. 34, pp. 1839-1840.

[3]. Egboka, B. (2004), "Gully erosion in Alaigbo" Osondu Newsletter, online Edition, Vol. 4. http://www.osondu.com/obec/erosionindex.htm last accessed 25th June, 2015

[4]. Fagbami, A. (1986), Remote sensing option for soil survey in developing countries ITC Journal, 1: pp 3.

[5]. Fairbridge, R. W. (2008), Erosion In: W. Chesworth (Ed.). Encyclopedia of Soil Science..Springer, Dordrecht, Netherlandspp. 216-22

[6]. Kakembo, V., Xanga, WW \& Rowntree, K 2009, 'Topographic thresholds in gully development on the hillslopes of communal areas in Ngqushwa Local Municipality, Eastern Cape, South Africa', Geomorphology, vol. 110, no. 3-4, pp. 188-194.

[7]. Le Roux, JJ. Newby, TS \& Sumner, PD 2007, 'Monitoring soil erosion in South Africa at a regional scale: review and recommendations', South African Journal of Science, vol. 103, pp. 329-335.

[8]. Melesse, A. M. and Jordan, J. D.(2002),A comparison of fuzzy vs. Augmented-ISODATA Classification Algorithms For Cloud-Shadow Discrimination From LANDSAT

[9]. Nachtergaele, J., Poesen, J., OostwoudWijdenes, D. V and AndekercKhove, L. (2002), Medium Term evolution of a Gully Developed in a Loess-derived soil Geomorphology,46, No. 3-4, pp. 223-239.

[10].Nwanko, and Ifeadi, (1996), "Ogunpa Flood disaster and Environmental Problems or Cultural Fiction" Amam Journal 4 Society, Culture and Environment Vol. 4 Pp 110-121

[11].Nuket, B. (2009), Using Geographic Information System and Remote Sensing Techniques for Soil Erosion Assessment: Polish J. of Environ. Stud. Vol. 19, No 5 (2010), 881 - 886

[12].Rebeiro-Hargrave, A. (2000), Large Scale Modelling of Drainage Network Evolution in a Tectonically Active Environment: 323p. Ph.D. Thesis, University of London

[13].Stocking, M \& Murnaghan, N 2000, Land degradation - guideline for field assessment, Norwich: Overseas Development Group, England, University of East Anglia. 